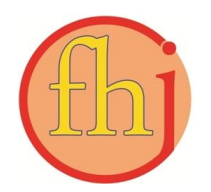

Faletehan Health Journal, 6 (3) (2019) 83-90

www. journal.Ippm-stikesfa.ac.id/ojs/index.php/FHJ

ISSN 2088-673X | e-ISSN 2597-8667

\title{
Studi Fenomenologi: \\ Pelaksanaan Patient Center Care Perspektif Pasien dan Perawat di RS dr. Dradjat Prawiranegara Serang
}

\author{
Eka Ernawati ${ }^{1 *}$, M ilawati Lusiani $^{1}$ \\ 1Program Studi IImu Keperawatan, Fakultas IImu Kesehatan, Universitas Faletehan \\ *Corresponding Author: ekakeysha@yahoo.co.id
}

\begin{abstract}
Abstrak
Pelayanan keperawatan merupakan salah satu kebutuhan yang harus dilaksanakan dalam sebuah organisasi pelayanan kesehatan di Indonesia. Pelayanan keperawatan yang berfokus pada pasien atau biasa disebut PCC (Patient Centered Care) merupakan pendekatan membina hubungan timbal balik antara penyedia pelayanan dan pasien. Tujuan penelitian untuk mengetahui fenomena pelaksanaan PCC perspektif pasien dan perawat. Desain dalam penelitian menggunakan kualitatif dengan pendekatan deskriptif naratif. Hasil penelitian mendapatkan tema yang muncul dari partisipan pasien terdiri dari: kurang informasi kesehatan yang diterima dan perlakuan yang kurang care dalam perawatan; pasien kurang mengenal kondisi diri dan sugesti dengan pengobatan tradisional; dukungan keluarga yang dibutuhkan pasien. Sedangkan tema yang muncul dari partisipan perawat terdiri dari: pengenalan yang kurang mengenai PCC dan asuhan keperawatan kurang optimal; tim khusus untuk referral/ rujukan pasien ke tingkat selanjutnya; penyampaian informasi kesehatan dari tenaga kesehatan. Penelitian ini merekomendasikan perlu peningkatan pemahaman PCC kepada pemberi pelayanan dan pasien, agar RS bisa membentuk sistem rujukan khusus untuk pasien ke pelayanan selanjutnya. Kata Kunci: Patient Center Care. Perawat, Pasien
\end{abstract}

\begin{abstract}
Nursing service is one of the requirements that must be implemented in a health care service provider in Indonesia. Patient-centered care (PCC) is an approach that fosters patient-centered health care. It is an approach to fostering reciprocal relationships between service providers and patients. The aim of the study was to determine the phenomenon of the implementation of PCC in the perspective of patients and nurses. The design in the study used a descriptive narrative qualitative design. The results of the study found the themes that emerged from patient participants consisted of: lack of health information received and treatment that lacked care in care; patients are not familiar with their condition and suggestions with traditional medicine; family support needed by patients. While the themes that emerged from nurse participants consisted of: Less recognition of PCC and less optimal nursing care; special team for patient referrals / referrals to the next level; delivering health information from health workers. This study concluded that it was necessary to increase the understanding of PCC to service providers and patients. So that hospitals can form a special referral system for patients to further services.
\end{abstract}

Keywords: Patient Center Care. Nurse, Patient 


\section{Pendahuluan}

Rumah Sakit adalah institusi pelayanan kesehatan yang diberikan terhadap seseorang, keluarga atau kelompok secara paripurna dengan menyediakan pelayanan rawat inap, rawat jalan, dan gawat darurat. Di Indonesia rumah sakit sebagai salah satu sistem pelayanan kesehatan yang secara garis besar memberikan pelayanan untuk masyarakat berupa pelayanan kesehatan mencakup pelayanan medik, pelayanan penunjang medik, rehabilitasi medik dan pelayanan keperawatan (Herlambang, 2016).

Pelayanan keperawatan di rumah sakit harus mengacu pada aturan dan norma yang berlaku. Setiap tindakan harus berdasar pada SOP (Standar Operasional Prosedur). Pelayanan keperawatan perlu diberikan secara komprehensif. Kebutuhan pasien sebagai mahluk bio-psiko, sosio, kultural harus dipenuhi. Pelayanan keperawatan sebagai pelayanan profesional merupakan pelayanan yang bersifat humanistik yang dilaksanakan berdasarkan ilmu dan kiat yang berorientasi kepada kebutuhan pasien, baik secara individu, keluarga, kelompok, maupun komunitas yang dilandasi etika keperawatan (Dwiyanti, 2014).

Pelayanan yang berfokus pada pasien atau biasa disebut PCC (Patient Centered Care) merupakan pendekatan untuk membina hubungan timbal balik antara penyedia pelayanan dan pasien sehingga akan mengurangi konflik yang selama ini timbul sebagai akibat sedikitnya komunikasi dan informasi (Kusumaninggrum, 2009). Penerapan PCC di rumah sakit harus melibatkan semua aspek, yaitu dari pimpinan, dokter, perawat, sampai tenaga non-medis. Strategi-strategi yang dapat dilakukan dalam pelaksanaan PCC antara lain: pelatihan leadership, pemberian penghargaan dan insentif serta pelatihan untuk perbaikan mutu. Selain itu, PCC juga dapat meningkatkan otonomi pasien dan pemberdayaan tenaga kesehatan untuk merencanakan dan menjalankan pekerjaan mereka sesuai dengan kebutuhan pasien (Framptom, 2008).

Di Indonesia penelitian yang dilakukan Hany (2015) di RSUD Syech Yusuf Gowa di peroleh hasil bahwa adanya hubungan antara kinerja perawat pelaksana dengan kepuasan pasien. Kurangnya pelayanan kesehatan yang diberikan oleh perawat pelaksana kepada pasien sehingga $70 \%$ dari $100 \%$ pasien rawat inap kelas 111 menyatakan tidak puas dengan pelayanan yang diberikan. Sedangkan penelitian yang dilakukan oleh Rahma dan Wiko (2011) dalam Nurrizka, R. H. (2011) melakukan penelitian di RSUD Achmad Mochtar, di peroleh hasil bahwa pemberian pelayanan pada ruang rawat inap kelas 11 dan 111 berada pada tingkat yang rendah, akan tetapi pelayanan yang diberikan pada kelas 1 menunjukan angka yang tinggi di bandingkan dengan kelaskelas lainnya. Berdasarkan perbedaan dari kedua jurnal tersebut bahwa Rendahnya pelayanan yang diberikan kepada ruang rawat inap kelas 11 dan 111 diperkirakan karena tidak terpenuhinya ekspektasi masyarakat terhadap suatu pelayanan kesehatan.

Marti, Andarini, dan Lestari (2016) mengemukakan terkait penerapan prinsip PCC saat proses resusitasi, hasil penelitian ditemukan enam hal sebagai hambatan atau tantangan yang dihadapi oleh tim resusitasi dalam penerapan prinsip patient centered care selama proses resusitasi. Diantaranya variasi bahasa dan unsur kepercayaan,faktor keluarga, kompetensi rekan kerja yang kurang, terbatasnya sarana dan prasarana serta beban kerja. Menurut McCormack dan McCance (2006) hasil penelitian menunjukan bahwa patient center care berpusat pada empat konstruksi - prasyarat, yaitu berfokus pada perawat, lingkungan perawatan, dimana perawatan diberikan, proses yang berpusat pada pasien dengan fokus memberikan perawatan melalui berbagai aktifitas, serta hasil proses keperawatan.

Berdasarkan hasil studi pendahuluan yang dilakukan di RS dr. Dradjat Prawiranegara Serang, bahwa data dari RS dr. Dradjat Prawiranegara tentang komplain dari pasien, terkait kepuasan pelayanan yang diberikan, alur penerimaan pasien yang dirasakan sudah baik namun masih kurang dalam melayani. Kemampuan perawat dalam mendokumentasikan asuhan masih dirasakan kurang optimal. Berdasarkan hasil penelusuran dan telaah jurnal diatas, peneliti tertarik untuk meneliti bagaimana "Studi fenomenologi pelaksanaan patient center care: perspektif pasien dan perawat di ruang rawat inap RS dr. Dradjat Prawiranegara Serang tahun 2017”.

\section{Metode Penelitian}

Desain penelitian ini dilakukan dengan menggunakan metode kualitatif dengan pendekatan naratif deskriptif. Menjelaskan peristiwa dapat dilakukan secara sistematis dengan mengedepankan data yang aktual. Fenomena 
Faletehan Health Journal, 6 (3) (2019) 83-90 www. journal.Ippm-stikesfa.ac.id/ojs/index.php/FHJ ISSN 2088-673X | e-ISSN 2597-8667

disajikan secara apa adanya tanpa manipulasi dan peneliti tidak mencoba menganalisis bagaimana dan mengapa fenomena tersebut bisa terjadi, oleh karena itu penelitian jenis ini tidak memerlukan adanya suatu hipotesis (Nursalam, 2008).

Pemilihan partisipan penelitian berdasarkan kriteria dan diseleksi melalui proses rekruitmen. Rekruitmen dilakukan dengan metode purposive sampling, dimana peneliti sengaja memilih partisipan kerena dianggap mempunyai karakteristik tertentu, yang dapat memperkaya data penelitian. Partisipan yang diambil oleh peneliti adalah pasien yang telah dirawat diruang medikal ataupun bedah., sedangkan kriteria responden perawat adalah perawat yang berdinas di ruang (Anggrek 1, Tulip, Cempaka, dahlia, dan Anggrek 2). Seorang perawat yang telah menjadi Ketua Tim asuhan dan pelayanan. Pasien dan perawat kooperatif saat wawancara berlangsung dan bersedia menjadi partisipan.

Dalam penelitian ini pengumpulan data menggunakan alat perekam suara dengan menggunakan Hp Vivo Youth. Pada saat wawancara, peneliti menggunakan teknik wawancara mendalam (In-depth Interview) dengan jenis pertanyaan semi terstruktur untuk menggali pengalaman partisipan. Peneliti Selalu mengajukan pertanyaan terbuka diawal wawancara. Namun jika partisipan kesulitan memberikan jawaban, maka peneliti memberikan pertanyaan dalam bentuk lain (misalnya memberikan contoh-contoh yang relevan dengan pertanyaan) untuk memfasilitasi partisipan menjawab pertanyaan. Apabila jawaban pastisipan belum jelas, peneliti memvalidasi jawaban partisipan dengan teknik pertanyaan klarifikasi.

\section{Hasil dan Pembahasan}

Data partisipan pasien didapat 4 partisipan antara 43 tahun sampai 60 tahun. Dengan jenis kelamin 3 perempuan dan 1 laki-laki. Mempunyai pengalaman dirawat diruang medik ataupun bedah. Dengan lama rawat antara $7-10$ hari. Sedangkan data partisipan perawat yang berdinas diruang Cempaka, Anggrek 2, Tulip, Dahlia dan Melati 2. Partisipan perawat merupakan perawat yang bertugas sebagai Ketua Tim Asuhan keperawatan diruangan Masing-masing. Dengan jenjang pendidikan diploma dan profesi ners keperawatan.

Analisis data menghasilkan 3 tema yang berasal dari partisipan pasien dan 3 tema berasal dari partisipan perawat. Tema yang muncul dari partisipan pasien terdiri dari: kurang informasi kesehatan yang diterima dan perlakuan yang kurang care dalam perawatan, pasien kurang mengenal kondisi diri dan sugesti dengan pengobatan tradisional, dan dukungan keluarga. Sedangkan tema yang muncul dari partisipan perawat terdiri dari: pengenalan yang kurang mengenai PCC dan asuhan keperawatan kurang optimal, tim khusus untuk referral/ rujukan pasien ke tingkat selanjutnya, dan penyampaian informasi kesehatan dari tenaga kesehatan.

Hasil penelitian ditemukan pernyataan dua dari empat partisipan merasa kurang menerima informasi mengenai status kesehatan selama dirawat, terbukti dari ungkapan pasien :

..dulu bingung karena kurang informasi jadi kita harus nanya ke yang lain (Ps1)..

...pengenya mah terus terang aja gitu ibaratnya kan saya banyak yang kenal kalau tidak sampaikan ke saya penyakit saya ini ini gitu (Ps3)..

...Cuma ada satu atau dua perawat entah itu karena dia kondisi cape atau apa kadang ada pelayanan yang kurang, ketika ada sesuatu yang tidak saya pahami ketika saya nanya kesanya perawat tidak merespon dengan baik tapi itu hanya 1 atau 2 perawat (Ps1).. saya sudah tahu perawat yang itu jika ditanya seperti itu jadi saya tidak akan nanya lagi saya nanya ke perawat yang lain (Ps1).

..ada yang baik ada yang kurang baik terus pelayananya agak lama. Pengenya mh baik semua kalo kita datang biasa aja senyum kan enak ga bikin tegang (Ps2)...

..kurang ramah kalau menurut saya, tapi sebagian ada yang baik semuanya juga baik sih untuk (P4)..

Hasil penelitian ditemukan pernyataan yang menujukan semua partisipan kurang mengerti dengan kondisi penyakit yang dialami. Setelah sakit baru berobat, dan sugesti yang telah dilakukan adalah pengobatan tradisional.

.. tahunya dari orang nyoba-nyoba aja kesitu di urut minum jamu terus malamnya langsung kaki kaya bengkak sakit(P1)...

..kadang minum daun cery kata tetangga bisa menurunkan gula darah ga sering Cuma nyoba $\operatorname{saja}(P 2)$..

.saya diem aja kan, namanya saya juga jarang makan, sehari itu paling minum kopi hitam (P3)... Sudah dapat 3 hari saya kaki saya ko bengkak kan kaget yah (P3) 
sakit yang di rasakan mah Cuma pusing aja dikepala terus mual kadang-kadang ibu kalau makan suka telat, kalau banyak makanan mual kalau ga makan perih,itu efeknya mah dari magh kali yah (P4)

Hasil penelitian ditemukan pernyataan yang menunjukan semua partisipan mendapatkan dukungan keluarga, agar bisa semangat dan bertahan dengan kondisi sakitnya.

..selama sakit dukungan suami, anak, saudara mendukung sih (P1)..

..Alhamdulillah ya mereka mendukung (keluarga) (P2)..

..Alhamdulillah masih banyak orang yang perhatian sama saya. (P3)..

..tetangga biasa pada datang ke ibu jengukin (P4).

Hasil penelitian ditemukan pernyataan yang menujukan empat dari lima partisipan perawat mengatakan kurang mengenal istilah PCC dan alurnya, sehingga asuhan keperawatan dirasakan kurang optimal.

... temen-temen yang kuliah juga kan kalau sharing belum pernah mendengar PCC baru ini mendengar (Prwt 1)...

..lupa-lupa ingat bu, setahu saya PCC itu mencangkup asuhan keperawatan berfokus pada pasien. Apa yang di keluhkan pasien, kalau kita akan memberikan tindakan atau asuhan keperawatan pasien dan keluarga harus dilibatkan (Prwt 3)..belum pernah dengar PCC bu (Prwt 5)..

kalau di ruangan untuk PCC ini mungkin sudah berjalan. Belum familiyar sama PCC..yah sama saja, mungkin untuk pembagian perawat sesuai kebutuhan pasien. Misalnya pasien total ada berapa nanti kita bagi dulu perawatnya (Prwt 1)

Kayanya belum masuk PCC nih (Prwt 2)

...asuhan keperawatan kadang kepegang kadang engga (Prwt 3)..

...kalau di tulip jujur engga, karena emang saya engga ke pegang soap aja kadang engga soalnya kadang pelaksana Cuma satu kadang 2 baru ke pegang kalau lagi sendiri susah, tindakan, belum intruksi dokter, scanning, EHO ini itu sudah makan waktu dan tenaga di tambah saya aja kadang visit hampir semua katim (Prwt4)..

..kalau di cempaka sih pelaksanaanya lengkap biasanya askep saya cek dari awal apa yang kurang sampai ke SOAPnya (Prwt3)..

... terus masalah discharge planning selama ini kita ngisi salahnya kita mengisi diwaktu pasien mau pulang harusnya discharge planning itu di isi dari awal (Prwt 2)..

Hasil penelitian ditemukan pernyataan yang menunjukan dua dari lima partisipan membutuhkan sistem referal yang jelas dalam merujuk pasien.

...kesulitanya yah begitu pasien rujuk seтиa, biasanya kan interna kebanyakanya di rujuk, di rujuk jugakan gampang-gampang susah yah bu itu kendalanya. ... dan harus di antar perawat itu harus di pastikan tempatnya ada dulu itu yang menjadi kendala dan keluarga tidak boleh di libatkan disana untuk mencari ruangan. Harusnya ada tim rujuk tersendiri dari rumah sakit. Selama ini masih dari ruangan. (Prwt 5)...

...sudah di tulis nama-nama keluarga pasien nanti yang bakal menemani tapi itu tidak bertahan lama hanya 1 bulan ( Prwt4)...

Hasil penelitian ditemukan pernyataan yang menunjukan satu dari lima responden mengatakan pemberian informasi harus diberikan dengan jelas pada pasien dan keluarga.

...dokter selalu ngasih tau kondisi pasien, misalkan pasien ini kondisinya kurang baik nih gitu, memberikan arahan kepada pasien atau keluarga pasien bahwa harus begini gitu. Komunikasi menurut saya sudah bagus (Prwt 2) ada juga karena dokternya yang kadang tidak mau ada keluarga pasien saat sedang visit, padahalkan keluarga pasien sebenarnya ada yang pengen tahu perkembangan pasien seperti apa, tapi ada juga dokter yang melibatkan keluarga pasien. (Prwt 2)...

Hasil penelitian ditemukan pernyataan dua dari empat partisipan merasa kurang menerima informasi mengenai status kesehatan selama pasien dirawat. Pemberian informasi kesehatan kepada pasien dan keluarga merupakan hak pasien dalam memperoleh informasi mengenai proses pelayanan, informasi medis dan diagnosa pasien, rencana pengobatan penyakit serta pelayanan lain selama pasien di rawat di rumah sakit. Tujuan pemberian informasi kesehatan pada pasien dan keluarga adalah untuk melibatkan pasien dan keluarga dalam mengambil keputusan terhadap tindakan atau proses pelayanan (Suryawati. 2004).

Pemberian informasi kesehatan di lakukan oleh petugas kesehatan yang berperan dalam memberikan asuhan dan pelayanan di rumah sakit. Hasil penelitian ini sejalan dengan penelitian yang dilakukan (Yosafianti, \& Alfiyanti. 2010). Tentang pemberian pemberian pendidikan kesehatan 
Faletehan Health Journal, 6 (3) (2019) 83-90

www. journal.Ippm-stikesfa.ac.id/ojs/index.php/FHJ

ISSN 2088-673X | e-ISSN 2597-8667

persiapan pasien pulang terhadap kepuasan pasien tentang pelayanan keperawatan di RS Romani Semarang dari penelitian didapatkan pasien merasa puas setelah mendapatkan pendidikan kesehatan.

Pelayan kesehatan saat ini sangat dibutuhkan oleh masyarakat. Pemberian pelayanan yang baik menuntut perawat sebagai advokat. Peran perawat sebagai advokat adalah memfasilitasi pasien dan keluarga untuk mendapat pelayanan yang sesuai dan sama. Pasien membutuhkan perlindungan dari perawat ketika seseorang sakit, kekuatan fisik dan mentalnya menurun. Pasien yang dalam kondisi lemah, kritis dan mengalami gangguan membutuhkan seorang advokat yang dapat melindungi kesejahteraannya (Afidah \& Sulisno. 2013).

Hasil tema dari pasien yang peneliti ditemukan, menjadi salah satu faktor yang mempengaruhi penilaian kepuasan pasien dan keluarga terhadap pelayanan yang ada di rumah sakit. Kecepatan Pelayanan serta pemberian informasi tentang kesehatan yang di butuhkan merupakan pelayanan utama yang di berikan rumah sakit. Jika dalam menerima informasi kesehatan pasien dan keluarga kurang maka akan mempengaruhi penilaian dan kepuasan pasien dalam pelayanan rumah sakit.

Budaya di Indonesia, khususnya masyarakat daerah Serang dengan partisipan adalah seorang istri ataupun suami pencarian informasi mengenai kesehatan masih belum dirasakan penting. Pengetahuan yang didapat partisipan mengenai penyakitnya hanya sebatas mengetahui bagaimana penyakit tersebut muncul, pencegahan dan pengobatan yang harus dilakukan.

Ketidaktahuan mencari informasi mengenai penyakitnya kemudian mencari tahu adalah proses belajar. Proses belajar tersebut sesuai dengan teori experiental learning. Menurut teori experiental learning yaitu proses pengetahuan terbentuk melalui transformasi pengalaman. Belajar dari pengalaman mencakup keterkaitan antara dua hal yaitu berbuat dan berpikir. Proses yang didapatkan melalui kombinasi antara pengalaman dengan mentransformasi pengalaman itu sendiri (Kolb, et al., 2001).

Penilaian dan kepuasan pasien dalam pelayanan Rumah Sakit hendaknya meningkatkan dan menerapkan penggunaan Caring. Caring merupakan inti atau fokus dalam keperawatan sebagai bentuk praktis keperawatan profesional. Hasil tema dari pasien ditemukan, bahwa perilaku yang kurang care di dalam perawatan. Di temukan beberapa pasien yang mendapatakan perilaku kurang care selama proses perawatan. Perilaku kurang care menyebabkan rendahnya penilaian kepuasan pasien terhadap pelayanan rumah sakit.

Hubungan caring perawat dengan kepuasan pasien menunjukan bahwa terdapat kecenderungan, semakin perilaku caring perawat baik menunjukan bahwa terjadi kepuasan yang tinggi. Perilaku perawat yang kurang caring akan mempengaruhi kepuasan pasien yang rendah (Jones.2008) menjelaskan bahwa untuk menciptakan sebuah kepercayaan pasien kepada dokter atau perawat adalah dengan menciptakan waktu bersama dengan pasien. Hal ini sejalan dengan penelitian yang dilakukan oleh Sukesi. (2013). Mengenai upaya peningkatan caring perawat terhadap kepuasan pasien diruang rawat inap RS Permata Medika Semarang. Didapatkan hasil perawat yang berprilaku caring kepada pasien memberikan kepuasan pasien saat dirawat dirawat.

Hasil penelitian ditemukan pernyataan yang menujukan semua partisipan kurang mengerti dengan kondisi penyakit yang dialami. Setelah sakit baru berobat, dan sugesti yang telah dilakukan adalah pengobatan tradisional. Keadaan yang terjadi pada Partisipan adalah datang ke Rumah Sakit dengan kondisi yang membutuhkan tenaga kesehatan. Pola kebiasaan masyarakat yaitu membutuhkan perawatan bila dalam kondisi sakit parah. Keadaan tersebut menurut Kristina, \& Sudjaswadi. (2007) masyarakat mencari pengobatan antara lain ke puskesmas, paramedis, dokter praktik, rumah sakit, balai pengobatan, dan pengobatan tradisional.

Pengobatan sendiri adalah melakukan pengobatan dengan menggunakan obat ataupun herbal dengan tujuan untuk mengurangi gejala tanpa resep/intervensi dokter. Pengobatan sendiri dalam hal ini dibatasi hanya untuk obat-obat modern yaitu obat bebas dan obat bebas terbatas (Kristina, \& Sudjaswadi. 2007). Ini di sebabkan karena kurangnya informasi kesehatan yang diterima pasien dan keluarga sehingga pasien kurang mengenali kondisi diri. Kurangnya komunikasi antara dokter dan perawat terhadap pasien dan keluarga menimbulkan sugesti pasien untuk melakukan pengobatan tradisional. Kondisi diatas menunjukan kurangnya komunikasi antara dokter, perawat dan pasien ini dapat menyebabkan kurangnya kepuasan pasien terhadap pelayanan rumah sakit yang ada (Suryawati. 2004). 
Hasil penelitian ditemukan pernyataan yang menunjukan semua partisipan mendapatkan dukungan keluarga, agar bisa semangat dan bertahan dengan kondisi sakitnya. Dukungan keluarga menurut Friedman (2010), adalah sikap, tindakan penerimaan keluarga terhadap anggota keluarganya. Hasil tema dari pasien di temukan bahwa, dukungan keluarga terhadap pasien berperan sangat baik dan selalu mendukung untuk kondisi kesehatan pasien atau anggota keluarga. Bahkan dari beberapa pasien di temukan yang mengambil keputusan terhadap proses perawatan pasien adalah keluarga.

Dukungan sosial sangat dibutuhkan oleh pasien terutama saat menjalani pengobatan. Terjadi proses penyesuaian diri terhadap penyakit sangat dipengaruhi oleh ketersediaan sumber dukungan dan sosial (Catz. 2000; DiMatteo, \& Kravitz. 1991). Salah satu bentuk dukungan yang dibutuhkan di lingkungan sosial adalah dukungan emosional berupa dihargai dan dicintai. Seseorang yang mengalami ataupun menghadapi masalah sangat membutuhkan dukungan keluarga (Ratna. 2010). Dukungan keluarga sebagai strategi preventif untuk mengurangi stress dimana pandangan hidup menjadi luas, dan tidak mudah stress.Dukungan keluarga adalah sikap, tindakan dan penerimaan keluarga terhadap penderita sakit.

Kebanyakan partisipan mendapatkan dukungan keluarga yang membantu proses penyembuhan. Dukungan keluarga yang diterima bisa dberupa fiansial/keuangan, support semangat, menemani pasien di RS untuk meningkatkan kenyamanan, mengantarkan pasien ke RS berobat jalan. Serta dukungan informasi, dimana keluarga mencari informasi kesehatan yang dibutuhkan pasien. Sistem dukungan yang signifikan, termasuk keluarga, teman, dan profesional kesehatan, memainkan peran kunci dalam meningkatkan kepatuhan dalam pengobatan, serta kondisi perbaikan terhadap penyakit.

\section{Gambaran tema dari partisipan perawat}

Hasil penelitian ditemukan pernyataan yang menujukan empat dari lima partisipan mengatakan kurang mengenal istilah PCC dan alurnya, sehingga asuhan keperawatan dirasakan kurang optimal. The Institute of Medicine (IOM) mendefinisikan Patient Centered Care sebagai perawatan kesehatan yang menetapkan kemitraan antara praktisi, pasien, dan keluarga pasien (jika sesuai) untuk memastikan bahwa keputusan menghormati keinginan, kebutuhan, dan preferensi pasien dan bahwa pasien berhak mendapatkan pendidikan dan dukungan untuk membuat keputusan dan berpartisipasi dalam perawatan dirinya (Shaller, D. 2007).

Menurut Australian Commision on Safety an Quality in Health Care (ACSQHC) Patient Centered Care adalah suatu pendekatan inovatif terhadap perencanaan, pemberian, dan evaluasi atas pelayanan kesehatan yang didasarkan pada kemitraan yang saling menguntungkan antara pemberi pelayanan kesehatan, pasien, dan keluarga. Patient Centered Care diterapkan kepada pasien dari segala kelompok usia dan bisa dipraktekan dalam setiap bentuk pelayanan kesehatan (Lumenta, 2012).

Penelitian ini sejalan penelitian yang dilakukan oleh Steward, et all (2010) dan Anderson EB (2002) menunjukkan bahwa pendekatan PCC dalam perawatan telah terbukti untukmeningkatkan status pasien. Pendekatan ini mengandalkan pondasi hubunganantara penyedia layanan dan pasien, peningkatan komunikasi, membina iklimpositif, dan mendorong pasien untuk berpartisipasi secara aktif dalaminteraksi antara keduanya.

Peningkatan pengetahuan serta perubahan sikap tentang penyakit dan pencarian pengobatan bagi masyarakat, dapat diberikan melalui penyuluhan serta sosialisasi program kesehatan, sehingga setiap masyarakat yang mengalami gangguan kesehatan akan berupaya mencari pengobatan. Tenaga kesehatan supaya memberikan pelayanan kesehatan sesuai dengan kebutuhan masyarakat (Rahayu. 2012).

Hasil penelitian ditemukan pernyataan yang menunjukan dua dari lima partisipan perawat membutuhkan sistem referal yang jelas dalam merujuk pasien. Perawat menyatakan mengalami kesulitan dalam rujukan pasien. Kesulitan terutama didaerah Rumah Sakit daerah terkait rujukan ke tingkat pelayanan selanjutnya. Kendala yang dihadapi berupa penerimaan pasien ditingkat selanjutnya, pasien perlu dipastikan bahwa penerimaan pasien tidak menyulitkan, proses administrasi yang masih sulit sejak Rumah Sakit awal kemudian Rumah Sakit yang dituju.

Kondisi tersebut membuat pelayanan masyarakat menjadi kurang bermutu. Sejalan dengan penelitian yang dilakukan oleh Luti, Hasanbasri \& Lazuardi (2012) mengenai upaya kebijakan dari Pemerintah Kabupaten Lingga dalam meningkatkan sistem rujukan. Kebijakan 
Faletehan Health Journal, 6 (3) (2019) 83-90 www. journal.Ippm-stikesfa.ac.id/ojs/index.php/FHJ ISSN 2088-673X | e-ISSN 2597-8667

pembiayaan meliputi dua aspek baik dari sisi demand (biaya pengobatan) dan dari sisi supply (sistem yang mendukung pelayanan kesehatan). Proses rujukan dari pelayanan kesehatan primer ke pelayanan tingkat lanjut telah berjalan baik walaupun masih ada kekurangan seperti belum memperhatikan aspek ketersediaan dan kelengkapan jenis pelayanan. namun networking dalam proses rujukan masih dilakukan secara parsial dan belum terintegrasi.

Salah satu prioritas reformasi kesehatan adalah meningkatkan dan pemerataan pelayanan yang bermutu bagi masyarakat di daerah terpencil dan kepulauan dengan berbagai rencana aksinya. Terbentuknya rencana aksi tersebut diharapkan pemenuhan kebutuhan pelayanan kesehatan dasar semakin terpenuhi, sehingga masyarakat di wilayah terpencil dan kepulauan akan terjamin kesehatannya (Luti, Hasanbasri, \& Lazuardi. 2012).

Untuk meningkatkan pemerataan pelayanan yang bermutu perlu rujukan dan alur yang jelas. Penelitian Carwoto \& Wijayanto (2013) mengenai Pengembangan dan implementasi sistem informasi jejaring rujukan kegawat daruratan maternalneonatal berbasis web dan sms (short message service). Hasil penelitian Sebuah sistem informasi jejaring rujukan kegawatdaruratan ibu bayi dan bayi baru lahir menggunakan teknologi web dan SMS (short message service). Mekanisme komunikasi dan operasionalnya menggunakan SMS yang sudah umum digunakan oleh tenaga kesehatan, sistem informasi ini memudahkan komunikasi antartenaga dan fasilitas kesehatan dalam menangani permintaan rujukan gawatdarurat.

Teknologi (short message service) mengalami proses pengujian teknis dan diujicobakan secara langsung pada jejaring rujukan kegawatdaruratan di dua kabupaten di Jawa Tengah. Hal tersebut terbukti dapat mencegah terjadinya penolakan atas permintaan rujukan oleh semua rumah sakit, mengupayakan pihak rumah sakit untuk menerima rujukan, serta mengurangi keterlambatan penanganan rujukan dalam jejaring pelayanan rujukan kegawatdaruratan maternal dan neonatal. Sistem informasi yang diimplementasikan juga dapat menjadi basis data yang bermanfaat bagi kepentingan pengambilan keputusan di rumah sakit maupun dinas kesehatan (Carwoto \& Wijayanto. 2013).
Hasil penelitian ditemukan pernyataan yang menunjukan satu dari lima responden perawat mengatakan pemberian informasi harus diberikan dengan jelas pada pasien dan keluarga. Berdasarkan hasil wawancara dan observasi di lapangan, proses penyampaian informasi dari tenaga kesehatan kurang optimal diberikan. Terbukti informasi yang diberikan kepada pasien membuat pasien bertanya-tanya tentang kondisi sakitnya. Sejalan dengan pernyataan pasien dari tema informasi kesehatan yang diterima dan perlakuan yang kurang care dalam perawatan.

Pemberian informasi kesehatan kepada pasien dan keluarga merupakan hak pasien dalam memperoleh informasi mengenai proses pelayanan, informasi medis dan diagnosa pasien, rencana pengobatan penyakit serta pelayanan lain selama pasien di rawat di rumah sakit. Tujuan pemberian informasi kesehatan pada pasien dan keluarga adalah untuk melibatkan pasien dan keluarga dalam mengambil keputusan terhadap tindakan atau proses pelayanan (Suryawati. 2004).

\section{Simpulan}

Hasil penelitian ini merekomendasikan RS dr. Dradjat Prawiranegara perlu meningkatkan keterampilan pemberi layanan kesehatan mampu menyampaikan proses informasi yang diberikan kepada pasien dan keluarga. Dibentuknya tim khusus untuk melakukan rujukan pasien ke tingkat selanjutnya. Perlu diberikan pelatihan dan pengenalan Patient Center Care kepada pasien ataupun perawat. Agar pelayanan yang diberikan menjadi dasar asuhan Patient Center Care.

\section{Referensi}

Afidah, E. N., \& Sulisno, M. (2013). Gambaran Pelaksanaan Peran Advokat Perawat di Rumah Sakit Negeri di Kabupaten Semarang. Jurnal Manajemen Keperawatan, 1(2).

Carwoto, C., \& Wijayanto, B. (2013). Pengembangan dan implementasi sistem informasi jejaring rujukan kegawatdaruratan maternal-neonatal berbasis web dan sms (short message service). Prosiding SNST Fakultas Teknik, 1(1).

Hany. (2015). Analisis Pengaruh Kualitas Pelayanan Terhadap Kepuasan Pasien yang Dimoderasi oleh variabel nilai. Diakses 20 Juli, 2017 dari http://repository.upnyk.ac.id

Kristina, S. A., Prabandari, Y. S., \& Sudjaswadi, R. (2007). Perilaku pengobatan sendiri yang 
rasional pada masyarakat. Berita Kedokteran Masyarakat, 23(4), 176.

Kolb, D. A., Boyatzis, R. E., \& Mainemelis, C. (2001). Experiential learning theory: Previous research and new directions. Perspectives on thinking, learning, and cognitive styles, 1 , 227-247.

Luti, I., Hasanbasri, M., \& Lazuardi, L. (2012). Kebijakan Pemerintah Daerah Dalam Meningkatkan Sistem Rujukan Kesehatan Daerah Kepulauan di Kabupaten Lingga Provinsi Kepulauan Riau. Jurnal Kebijakan Kesehatan Indonesia, 1(1).

Marti, E., Andarini, S., \& Lestari, R. (2016). Studi Fenomenologi Penerapan Prinsip Patient Centered Care pada Saat Proses Resusitasi di IGD Rsud Saiful Anwar Malang. The Indonesian Journal of Health Science, 6(1).

McCormack, B., \& McCance, T. V. (2006). Development of a framework for personcentred nursing. Journal of advanced nursing, 56(5), 472-479.

Nurrizka, R. H. (2011). Pengukuran indeks kepuasan masyarakat terhadap pelayanan kesehatan. Jurnal Manajemen Pelayanan Kesehatan, 14(01).

Nursalam. (2008). Konsep dan Penerapan Metodologi Penelitian Ilmu Keperawatan
Pedoman Skripsi, Tesis, dan Instrumen Penelitian Keperawatan. Jakarta: Salemba Medika Diakses 27 Maret 2017 dari https://books.google.co.id

Nursalam. (2010). Manajemen Keperawatan: Aplikasi dalam Praktik Keperawatan Profesional. Edisi 3. Jakarta : Salemba Medika.

Poerwandari, E. K. 2007. Pendekatan Kualitatif dalam Penelitian Psikologi. Jakarta: LPSP3 Universitas Indonesia.

Rahayu, D. A. (2012). Faktor-faktor yang berhubungan dengan pemilihan pengobatan tradisional di wilayah kerja puskesmas Muara Siberut kecamatan Siberut Selatan Kabupaten Kepulauan Mentawai Tahun 2012. Fakultas Kesehatan Masyarakat Universitas Andalas.

Suryawati, C. (2004). Kepuasan pasien rumah sakit (tinjauan teoritis dan penerapannya pada penelitian). Jurnal Manajemen Pelayanan Kesehatan, 7(04).

Sukesi, N. (2013). Upaya Peningkatan Caring Perawat Terhadap Kepuasan Pasien Diruang Rawat Inap RS Permata Medika Semarang. Jurnal Manajemen Keperawatan, 1(1).

Steward, M, et all. The impact of Patient Centered Care on Outcomes. PubMed. 2010 